\title{
Actual Problems of the Development of Technological Entrepreneurship in the Context of the Digital Transformation of the Economy
}

\author{
I. Arsakaev* \\ Chechen State University named after A.A. Kadyrov, Grozny, Russian Federation \\ *Corresponding author. Email: iarsakaev@inbox.ru
}

\begin{abstract}
The ongoing change in various sectors of the economy, taking place in connection with the scale of the process of transformation of the economic paradigm caused by the introduction of digital technologies, which directly affects entrepreneurship. Entrepreneurship is changing its essence, using an innovative high-tech idea as a competitive advantage. This article examines the concept of innovative technological entrepreneurship and its difference from traditional entrepreneurship, the quantitative and qualitative composition of innovations, the place of our country in the international innovation rating and the reasons for lagging behind the leading developed countries, as well as the problems of developing innovative technological entrepreneurship and ways to solve them.
\end{abstract}

Keywords: digitalization of economic processes, information technology, digital transformation of an enterprise, competitive advantages of an enterprise, optimization of business processes.

\section{INTRODUCTION}

Currently, scientific and technological progress has contributed to the rapid development of the information sphere. The transition from a traditional form to a digital economy, involving the use of digital technologies, is proceeding at a rapid pace in various industries.

Digitalization has affected all sectors of the economy, including entrepreneurship, especially its innovative, high-tech part. In this regard, the trends in the development of innovative technological entrepreneurship are very relevant.

In the modern world, economic activity based on digital technologies seems completely natural and meets the needs of the time. Various concepts and ideas for introducing the digital economy appear. Experts in various fields emphasize the need for the development of digital technologies, state a certain lag of Russia behind the world leaders in digitalization and formulate proposals on a system of measures to facilitate this process.

In order to have an idea of the prospects for legislative regulation of economic relations in the digital era, you need to get a clear idea of what the digital economy is, understand what challenges and what dangers it carries. Let's try to characterize the digital economy and the problems of the development of its legislative regulation from the standpoint of the science of business law.

The Strategy for the Development of the Information Society in the Russian Federation for 2017-2030, approved by Decree of the President of the Russian Federation No. 2034 dated May 9, 2017, contains the definition: volumes and the use of the analysis results of which, in comparison with traditional forms of management, can significantly increase the efficiency of various types of production, technologies, equipment, storage, sale, delivery of goods and services. " The opinion was expressed that the "digital" (electronic) economy is an economy that exists in a hybrid world (a new reality in which the real and virtual worlds are inextricably linked and all actions necessary for the real world can be performed through the virtual world). A characteristic feature of this economy is the maximum satisfaction of the needs of all its participants through the use of information5. Perhaps, the statement that the satisfaction of needs is carried out precisely through the use of information will cause some doubts. In reality, the essence of digital technology boils down to the ability to process, organize and use a huge amount of information. New carriers that have just appeared in the 
electronic era make it possible to accumulate knowledge in volumes that are impossible for the human brain under normal conditions [4].

Of course, information has always been important for the development of the economy and for business trade secrets, production, materials processing skills. But this information has never been of decisive importance and always fit into the concept of "human factor". In the digital age, information is no longer inextricably linked with a human carrier. It can be argued that the digital economy is a set of social relations that develop in the system of production, distribution, exchange and consumption, the interaction of whose subjects is based on the use of information. The term "digital economy" refers to various phenomena. Very often, even in the states - leaders of "digitalization", the digital economy is understood as the introduction of new forms of payments and communications. In essence, this is a simple digitization of existing economic relations. Such activity is important and useful, but it does not lead to the emergence of new forms of management and conceptually new economic relations. It is the development of new forms of management, the formation of economic relations based on the combination of the real and the virtual world, a qualitative change in public relations that can be considered the construction of a digital economy.

\section{THE ROLE OF INNOVATIVE TECHNOLOGY ENTREPRENEURSHIP AND ITS PLACE IN THE DIGITAL ECONOMY}

The program for the development of the digital economy in Russia until 2035 provides the following definition: "the digital economy is a set of social relations that develop in the process of using electronic technologies and infrastructure, as well as technologies for analyzing large amounts of data and forecasting, in order to optimize production, distribute consumption and increase the level of socio-economic development of the state "[1].

In the modern world, there is a special role of intellectual resources, openness of the economy, hightech production, customer focus, which must be taken into account by business entities for successful activities. Considering these features of the development of society and the economy, modern entrepreneurship is fundamentally different from the traditional one. At the end of the twentieth century, there was a separation of this type of entrepreneurship after the creation in the United States of such high-tech entrepreneurial structures as Apple, Google, Microsoft and many others.

Currently, the scientific discussion about the content of the concept of "innovative technological entrepreneurship" continues. According to O.G. Tikhomirova, technological entrepreneurship is the investment of capital (financial, intellectual, human) in the accumulation, use and distribution of specific assets based on modern achievements of scientific and technological knowledge in order to create and increase capitalization [8].

Under innovative technological entrepreneurship in a broad sense, G.V. Kadakoeva understands the process of creation and commercial use of technical and technological innovations [3]

E.S. Balashova, E.A. Gromova consider innovative technological entrepreneurship as the practical implementation of innovations, the introduction of advanced technologies in production, the use of new technical and technological processes in order to obtain a qualitatively new result [1-2].

Thus, innovative technological entrepreneurship can be characterized as a new business, which is based on a sustainable competitive advantage based on a high-tech innovative idea.

Therefore, the main advantage and source of profit in the case of innovative technology entrepreneurship is the availability of a new technology or device protected by a patent that competitors cannot replicate.

On the whole, Russia is still only on the verge of transition from a raw material model of the economy to an innovative one, therefore, the mechanism for the development of innovative technological entrepreneurship has not been determined. There are problems in the development of this type of entrepreneurship due to its location at the intersection of such components of the economy as the small and medium-sized business sector and the innovation sphere, which makes it difficult to take into account the specifics of this type of entrepreneurship in government programs and the low efficiency of social support measures [7].

\section{RESULTS AND DISCUSSION}

To date, there are two main digitalization strategies market and planned. Of course, these strategies do not exist anywhere in their pure form, methods of influence intersect and interact, but nevertheless, the general direction of influence in a particular country is reduced either to the development of digitalization in a natural way, with the predominance of dispositive regulation, or to building a digital economy under the patronage of the state. Two absolute world leaders in the digitalization process have chosen different strategies: the United States declares market development, China is focused on government regulation. What strategy should Russia choose? Here we are approaching the global issue of the prospects and trends in the development of Russian 
legislation, including legislation on entrepreneurial activity, which has always been raised by researchers lately6. In our opinion, it is more correct to act according to the Chinese model, allowing, where possible, market mechanisms [6-7].

In general, this approach is reflected in the Digital Economy of the Russian Federation program. In Russia, the degree of monopolization of markets is high, most of the GDP is created by organizations with a significant share of state participation, we do not have a technological and economic advantage over other countries. Therefore, we can hardly count on the evolutionary development of digitalization under the influence of a competitive market, the state is forced to direct, support and stimulate its development. There are quite a few digital technologies that, in the future, will have an increasing impact on human life and, accordingly, will affect the development of legislation. First of all, these are cognitive technologies, cloud technologies, the Internet of things, big data and digital currencies. Cognitive Technologies are capable of processing information in an unstructured form. Processing is taking into account many factors, the computer is capable of self-learning. If a conventional search engine, when asked on the Internet, gives out millions of links, then the use of cognitive processes will allow you to get a specific answer to the question posed. Cloud technologies are already widely used as a system of network access to the total amount of information that is remotely accessible. The Internet of Things (Internet of Things) and the Industrial Internet of Things (Industrial Internet of Things) are two large areas that involve the equipment of sensors and the connection to the Internet of all things and equipment important for life or for production. Management and control over processes occurs in real time. Big Data is the collective name for tools and methods for processing results [9]. A huge amount of information from an evergrowing number of sources will be systematized and processed in such a way that the user of the processed data will receive qualitatively new information about the phenomenon. Digital (electronic) currencies are already a reality of our time. A variety of electronic currencies are cryptocurrencies, the creation and circulation of which is associated with the use of cryptographic methods [8].

Blockchain technology (Block Chain, a chain of blocks of transactions) was created specifically for the first cryptocurrency - bitcoin, although now it already has an independent application. Virtual currency may not belong to cryptocurrencies and may not use blockchain technology (Yandex-money, Qiwi, WebMoney). Despite the negative attitude of many governments towards electronic money, it seems that in the future it is digital currencies that will be the main means of payment. Cryptocurrencies cannot be falsified or stolen. Minus - there is no single emission center, that is, there is no classical currency security by the issuer. Blockchain technology in the future should become one of the most demanded in business relationships, both vertical and horizontal. Blockchain is based on the fact that data is repeatedly duplicated and stored in a distributed network, its distortion is almost impossible: each record contains change history [10]. The technology is beginning to be applied in copyright fixing, in insurance business, and in crowdfunding.

The trend of Russian legislation in recent years is registration. It is the blockchain that is capable of qualitatively changing many registries - the Unified State Register of Legal Entities, Unified State Register of Legal Entities, audits, small and medium-sized businesses, etc. Moreover, in the future, it is quite possible to create commercial analogs of state registers, merging them with reference legal systems. The development of the latter based on cognitive technologies will lead to the creation of full-fledged robotic lawyers. Decisions (in government, business) will be made on the basis of huge amounts of information. Data from city cameras, information about activity on social networks, purchases through online cash registers - all information is collected and used. The main legal problem here is the observance of human rights, the protection of private life [12].

\section{CONCLUSIONS}

In the digital era, the interaction between the buyer and the seller will also fundamentally change, the classic constructions of buying and selling can at least fade into the background. Already now, the production of some goods can be ordered remotely according to your samples. In the future, this practice should spread, as a result, we will get a contractual design, when the former "seller" provides a service for the production of a certain object according to the technical parameters of the counterparty at its production facilities.

Accordingly, the usual distribution of rights, obligations and responsibilities of the parties to the contract will also change. In general, digital entrepreneurial turnover will be distinguished by the detailed recording of data on subjects and objects of economic relations. It is possible that for the purposes of advertising, government control, etc. in the future, in the chain "creation - distribution - exchange" there will be another link regulated by the norms of law "consumption". Also, most likely, digitalization (primarily blockchain technologies) will allow the acceptance of goods (fixing the execution of the contract) to become part of an electronic business contract. Another important problem to be solved specifically by lawyers is the definition of the legal regime of artificial intelligence. Can we talk about the legal personality of such an intellect? Can we imagine 
that artificial intelligence is an entrepreneur and has the corresponding responsibility?

The digital economy has important features that should not be forgotten - the continuity of information with carriers; dependence on energy sources. Therefore, a total transition to digitalization of all processes is possible only in conditions of energy security and independence. And - most importantly - digitalization does not replace industry! It is unlikely that Russia is interested in building a digitalized raw materials economy.

\section{FIGURES AND TABLES}

Table 1. Fundamental differences between innovative technology entrepreneurship and traditional entrepreneurship.

\begin{tabular}{|c|c|c|}
\hline $\begin{array}{c}\text { Compared } \\
\text { parameters }\end{array}$ & $\begin{array}{l}\text { Traditional } \\
\text { entrepreneurship }\end{array}$ & $\begin{array}{l}\text { Innovative technology } \\
\text { entrepreneurship }\end{array}$ \\
\hline $\begin{array}{c}\text { Supply and } \\
\text { demand ratio }\end{array}$ & $\begin{array}{c}\text { Satisfying } \\
\text { consumer demand }\end{array}$ & $\begin{array}{c}\text { Creation of a new supply } \\
\text { that generates demand }\end{array}$ \\
\hline $\begin{array}{c}\text { Improving the } \\
\text { efficiency of a } \\
\text { product or service }\end{array}$ & By reducing costs & $\begin{array}{c}\text { Creation of a } \\
\text { fundamentally new } \\
\text { product or technology }\end{array}$ \\
\hline Increase in profits & $\begin{array}{c}\text { By increasing the } \\
\text { volume of goods } \\
\text { or services }\end{array}$ & $\begin{array}{c}\text { By creating a new } \\
\text { product or technology }\end{array}$ \\
\hline
\end{tabular}

\section{REFERENCES}

[1] V.P. Samarina, Problems of introducing information and communication technologies into modern Russian industry, pp. 88-91 (2019).

[2] M. V. Maksimova, Organization of the execution of management decisions, 13(4) (2018) pp. 516518.

[3] R. Brailey, S. Myers, Principles of Corporate Finance, p. 132 (2020).

[4] A. Voronov, S. Rubanov, Sustainable development of the enterprise as a strategic goal of marketing, 3(2) (2018) pp. 31-37.

[5] E.V. Korchagina, Economic sustainability of an enterprise: types and structure. In: Problems of the modern economy, 3(15) (2018) pp. 68-71.

[6] Campbell Scientific Inc., Bowen Ratio system. Instruction manual. Logan, UT USA, p. 30 (2020).

[7] W.A. Dugas, Micrometeorological and chamber measurements of $\mathrm{CO} 2$ flux from bare soil Agricultural and Forest meteorology, pp. 115-128 (2018).

[8] A.S. Salamova, The theoretical foundations of institutionalism at the stage of accelerating globalization of international economic relations, 7 (2020) pp. 349-356

[9] J.J. Andrea, C. Burns, J. Touza, Renewable Energy as a Luxury? A Qualitative Comparative Analysis of the Role of the Economy in the EU's Renewable Energy Transitions During the 'Double Crisis'. Ecological Economics, 142 (2020) pp. 81-90.

[10] J. Yang, F. Zhang, X. Jiang, W. Sun, Strategic Flexibility, Green Management, and Firm Competitiveness in an Emerging Economy. In: Technological Forecasting and Social Change, 101 (2018) pp. 347-356

[11] K. Murtazova and M. Abdulkadirova, The Consumer Market in the New Economy, pp. 2-9 (2021). 